Article

\title{
Performance Assessment and Scooter Verification of Nano-Alumina Engine Oil
}

\author{
Yu-Feng Lue ${ }^{1}$, Yi-Hsuan Hung ${ }^{1, *}$, Fang-Sheng Li $^{1}{ }^{1}$, Tun-Ping Teng ${ }^{1, *}$, Syuan-Yi Chen ${ }^{2}$, \\ Chien-Hsun $\mathrm{Wu}^{3}$ and $\mathrm{Yu}$-Chang $\mathrm{Ou}^{1}$ \\ 1 Department of Industrial Education, National Taiwan Normal University, Taipei 10610, Taiwan; \\ yflue@ntnu.edu.tw (Y.-F.L.); fsli@outlook.com (F.-S.L.); a199079723@hotmail.com (Y.-C.O.) \\ 2 Department of Electrical Engineering, National Taiwan Normal University, Taipei 10610, Taiwan; \\ chensy@ntnu.edu.tw \\ 3 Department of Vehicle Engineering, National Formosa University, Yunlin County 632, Taiwan; \\ chwu@nfu.edu.tw \\ * Correspondence: hungyh@ntnu.edu.tw (Y.-H.H.); tube5711@ntnu.edu.tw (T.-P.T.); \\ Tel.: +886-960-002-226 (Y.-H.H.); +886-2-7734-3358 (T.-P.T.)
}

Academic Editor: Ichiro Minami

Received: 1 July 2016; Accepted: 8 September 2016; Published: 13 September 2016

\begin{abstract}
The performance assessment and vehicle verification of nano-alumina $\left(\mathrm{Al}_{2} \mathrm{O}_{3}\right)$ engine oil (NAEO) were conducted in this study. The NAEO was produced by mixing $\mathrm{Al}_{2} \mathrm{O}_{3}$ nanoparticles with engine oil using a two-step synthesis method. The weight fractions of the $\mathrm{Al}_{2} \mathrm{O}_{3}$ nanoparticles in the four test samples were 0 (base oil), $0.5,1.5$, and $2.5 \mathrm{wt}$. \%. The measurement of basic properties included: (1) density; (2) viscosity at various sample temperatures $\left(20-80{ }^{\circ} \mathrm{C}\right)$. A rotary tribology testing machine with a pin-on-disk apparatus was used for the wear test. The measurement of the before-and-after difference of specimen (disk) weight (wear test) indicates that the NAEO with 1.5 wt. $\% \mathrm{Al}_{2} \mathrm{O}_{3}$ nanoparticles (1.5 wt. \% NAEO) was the chosen candidate for further study. For the scooter verification on an auto-pilot dynamometer, there were three tests, including: (1) the European Driving Cycle (ECE40) driving cycle; (2) constant speed (50 km/h); and (3) constant throttle positions (20\%, 40\%,60\%, and 90\%). For the ECE40 driving cycle and the constant speed tests, the fuel consumption was decreased on average by $2.75 \%$, while it was decreased by $3.57 \%$ for the constant throttle case. The experimental results prove that the engine oil with added $\mathrm{Al}_{2} \mathrm{O}_{3}$ nanoparticles significantly decreased the fuel consumption. In the future, experiments with property tests of other nano-engine oils and a performance assessment of the nano-engine-fuel will be conducted.
\end{abstract}

Keywords: nanofluid; $\mathrm{Al}_{2} \mathrm{O}_{3}$; wear performance; engine oil

\section{Introduction}

Enhancing material performance by using nanoparticles already has considerable achievements in the past decades. Nanoparticles (nano-additives) are added to the working fluid to form nanofluids which have been widely used to enhance the thermal conductivity, heat transfer performance, and tribological properties of the working fluid [1-6]. In recent years, many researchers have added nanoparticles to oils in order to fabricate nano-oils that can improve the tribological properties of oil in order to enhance the operating efficiency and the life of machinery.

The nano-additives in nano-oils comprise various metal oxide nanoparticles $\left(\mathrm{Al}_{2} \mathrm{O}_{3}, \mathrm{CuO}\right.$, $\mathrm{TiO}_{2}$, and $\mathrm{ZnO}$ ) [7-11], metal nanoparticles ( $\mathrm{Cu}, \mathrm{Ag}$ ) [12-15], non-metal/metal oxide nanoparticles (graphite, boric acid, diamond, MWCNT/multi-walled carbon nanotubes) [13,14,16-18], and hybrid nanoparticles (MWCNT/ZnO and $\mathrm{SiO}_{2}$-MWCNTs) $[19,20]$. Most of the literature shows that nano-oils can reduce friction coefficients, power losses, wear, wear resistance, and can also improve the 
tribological performance of machinery. In addition, nano-oils had high thermal conductivity, enhancing heat dissipation caused by mechanical friction $[9,21]$. Therefore, adding nanoparticles into oils to enhance their mechanical properties was expected. Many studies showed that the viscosity of nano-oils was increased with the concentration of nanoparticles $[9,11,19,20,22]$. However, the effect of nanoparticle concentration on the increasing viscosity of nano-oils is gradually reduced with increasing nano-oil temperature $[9,19]$. Furthermore, the rheological properties of nano-oils exhibit Newtonian fluid behavior at low nanoparticle concentrations, while they show non-Newtonian fluid with shear thinning behavior at higher nanoparticle concentrations [22].

Operating performance evaluation of nano-oils in the actual operation of mechanical equipment has included refrigerators, vacuum pumps, internal combustion (IC) engines, gear rigs, bearings, etc. Lee et al. [23] used a fullerene nano-oil in a refrigerator, and found that the electric power consumption was reduced by decreasing the friction coefficient and wear rate to the compressor. Jwo et al. [24] used an $\mathrm{Al}_{2} \mathrm{O}_{3}$ nano-oil with various concentrations $(0.1 \%, 0.2 \%$, and $0.3 \mathrm{wt}$. \%) in a direct-drive oil-sealed rotary vacuum pump. The optimal condition showed that the temperatures of cylinder, case surface, and discharge pipeline were reduced by $1.3 \%, 1.7 \%$, and $3.8 \%$, respectively. The performance of IC engines in terms of frictional power loss, fuel consumption, oil consumption, and harmful exhaust emissions is closely related to the friction force and wear between moving parts of the engine, such as the piston assembly, valve train, and bearings. Generally, frictional losses in IC engines vary between $17 \%$ and $19 \%$ of the total indicated horse power [4]. Rasheed et al. [21] adopted graphene-based nano-oil in a four-stroke IC engine to investigate the coefficient of friction and the transfer rate of the engine. The results showed that the enhancement in thermal conductivity at $80^{\circ} \mathrm{C}$ and the heat transfer rate of the engine were $23 \%$ and $70 \%$, with a $21 \%$ reduction in the coefficient of friction of the piston rings by using a $0.01 \mathrm{wt}$. \% graphene-based nano-oil compared to the base oil (API20W50SN/CF). Choi et al. [13] observed that a graphite and silver nano-oil enhanced load-carrying and anti-wear properties in the Forschungsstelle fur Zahnrader und Getriebebau (FZG) gear rig test, and also reduced the electric power consumption by more than $3 \%$ compared to the base oil. Binu et al. [25] investigated the influence of $\mathrm{TiO}_{2}$ nano-oil on the load carrying capacity of a journal bearing. The results showed an increase in the load carrying capacity of a journal bearing using $\mathrm{TiO}_{2}$ nano-oil as compared to the base oils without nanoparticle addition.

The main role of nanoparticles added to oils is to improve mechanical performance due to effects such as: the rolling-sliding effect [26-28], protective film [29-31], third-body effect [26,32], mending and smoothing effect of surface roughness [14,26,33,34], cleaning effect on surfaces [35,36], and shear thinning of nano-oils $[9,19,22]$ that could be adopted to mitigate mechanical friction, to enhance anti-wear performance, and to facilitate the energy-efficient operation of machinery. The main advantages of incorporating nanoparticles into lubricants include their sizes and shapes, which are suitably adapted for a perfect feeding of the sliding interface, and for potentially reducing the friction coefficient and increasing the load-carrying capacity of coupled surfaces in mechanical systems $[13,15,22,25,36-38]$. Furthermore, using nanoparticles with high thermal conductivity to enhance the heat-transfer performance of lubricants can enhance the heat-dissipation performance of a mechanical system [21,39-41].

By literature survey, it can be found that studies of nano-oils focused primarily on the indexes of nano-oils characteristics itself, wear, friction coefficient, power consumption in the past. However, studies of IC engines with nano-oils for fuel efficiency (consumption) were rarely seen. In this study, ultrafine alumina $\left(\mathrm{Al}_{2} \mathrm{O}_{3}\right)$ nanoparticles were added to engine oil (EO), and a stable suspension was maintained to form nano-alumina $\left(\mathrm{Al}_{2} \mathrm{O}_{3}\right)$ engine oil (NAEO). The density, viscosity, specific heat, and tribological performance of the NAEO with various weight fractions of $\mathrm{Al}_{2} \mathrm{O}_{3}(0 \mathrm{wt}$. \%, $0.5 \mathrm{wt}$. \%, 1.5 wt. \%, and 2.5 wt. \%) were evaluated to assess the relevant characteristics. Finally, we conducted various real engine operation tests with the EO and NAEO to evaluate the practicability of NAEO in a 125 c.c. spark ignition engine of a scooter in a ECE40 driving cycle by analyzing the fuel consumption of a scooter using those oils. 


\section{Basic Properties and Wear Test}

\subsection{Basic Properties}

The NAEO was produced by mixing the $\mathrm{Al}_{2} \mathrm{O}_{3}$ nanoparticles (gamma phase, spherical shape, average particle size of $15 \mathrm{~nm}$ ) with the EO (SAE15W/40, API SL, GP, KYMCO, Kaohsiung, Taiwan) using a two-step synthesis method without any stabilizer. The weight fractions of the $\mathrm{Al}_{2} \mathrm{O}_{3}$ nanoparticles in the four test samples were $0 \mathrm{wt}$. \% (base oil), $0.5 \mathrm{wt} . \%, 1.5 \mathrm{wt}$. \%, and $2.5 \mathrm{wt}$. \%. The stirring and mixing devices of the two-step synthesis method consisted of a magnetic stirrer (PC420D, Corning, NY, USA), an ultrasonic bath (5510R-DTH, Branson, Danbury, CT, USA), and a high-speed homogenizer (YOM300D, Yotec, Hsinchu, Taiwan) for NAEO. The suspension performance of NAEO was evaluated by a static testing method (static position) for 15 days. The basic properties of NAEO include: (1) density; (2) viscosity; (3) specific heat at various sample temperatures (20, 30, 40, 50, 60,70 , and $80^{\circ} \mathrm{C}$ ) with various weight fractions of $\mathrm{Al}_{2} \mathrm{O}_{3}$. The constant temperature of test samples for density and viscosity tests was controlled by a thermostatic bath (P-20, YSC, Hsinchu, Taiwan). For the densities with different weight fractions of $\mathrm{Al}_{2} \mathrm{O}_{3}$, the weight of a sample was measured by an electronics balance (XS-1220M, Precisa, Dietikon, Switzerland) with an electronic pipette (5 mL, Eppendorf, Germany) to measure the sample weights of a fixed volume $(5 \mathrm{~mL})$ to determine the densities of test samples. For viscosity tests, a resonant viscometer (VL700-T15, Hydramotion, Malton, UK) was used to test the viscosities of all samples. The specific heat of the sample was measured using a differential scanning calorimeter (DSC, Q20, New Castle, TA, USA) equipped with a vapor compression refrigeration system (RCS40, New Castle, TA, USA) filled with high-purity nitrogen $(5 \mathrm{~N})$ atmosphere. The specific heat test method was a standard reference approach, in which the standard reference was sapphire (TN8, $61.48 \mathrm{mg})$ [42].

\subsection{Wear Test}

A rotary tribology testing machine with a pin-on-disk apparatus conducted a wear test to evaluate the anti-wear performance of each sample (EO and NAEO). In Figure 1, the testing machine (7085, Sensetek, Kaohsiung, Taiwan) was at the left-hand side, where the test procedures referred to [43-45]. The control panel was in the middle, where the chamber temperature, normal force, and rotational speed of the platform could be set and controlled. An electronic balance (XS-125A, Precisa, Dietikon, Switzerland) was used to measure the weight difference of the disk (wear loss) before and after the wear test. Figure 2a shows the pin-on-disk chamber, while in Figure $2 b$, the disk (22 $\pm 0.5 \mathrm{~g})$ was composed of bearing steel ( $\phi=32 \mathrm{~mm}$, SUJ2) and three carbon steel balls ( $6 \mathrm{~mm}$, AISI 1045) that were fixed to the turntable as the pin. The pin-on-disk apparatus was fixed on the rotary tribology testing machine to perform the wear test. The disk has a flange to prevent the outflow of EO or NAEO of test samples, and therefore it could minimize the starvation effect in the wear test. The 0.5 c.c. test sample was dropped onto the disk, and then the wear test was conducted at various rotating speeds (500-1000 rpm) and normal forces (200-450 N). The total number of rotations was fixed at 10,000. The wear loss between the original disk and the final one can be derived to evaluate the anti-wear performance of EO and NAEO. 


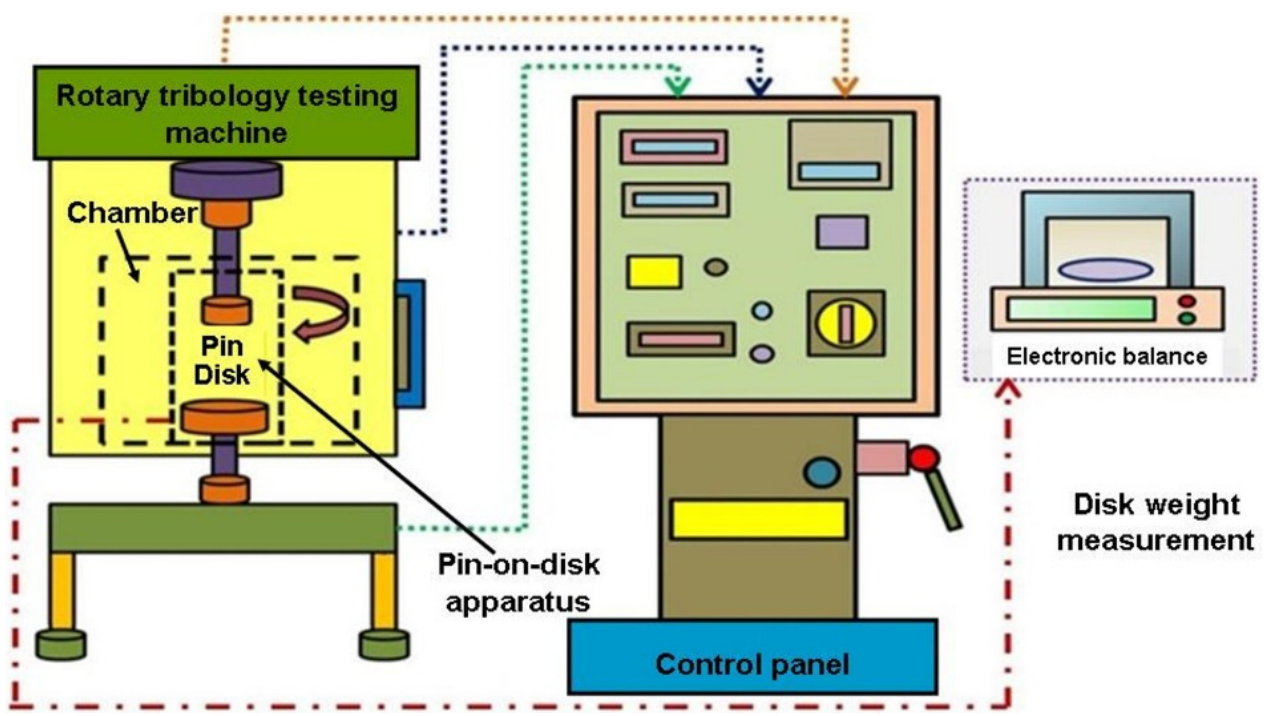

Figure 1. Experimental setup of the wear test machine.

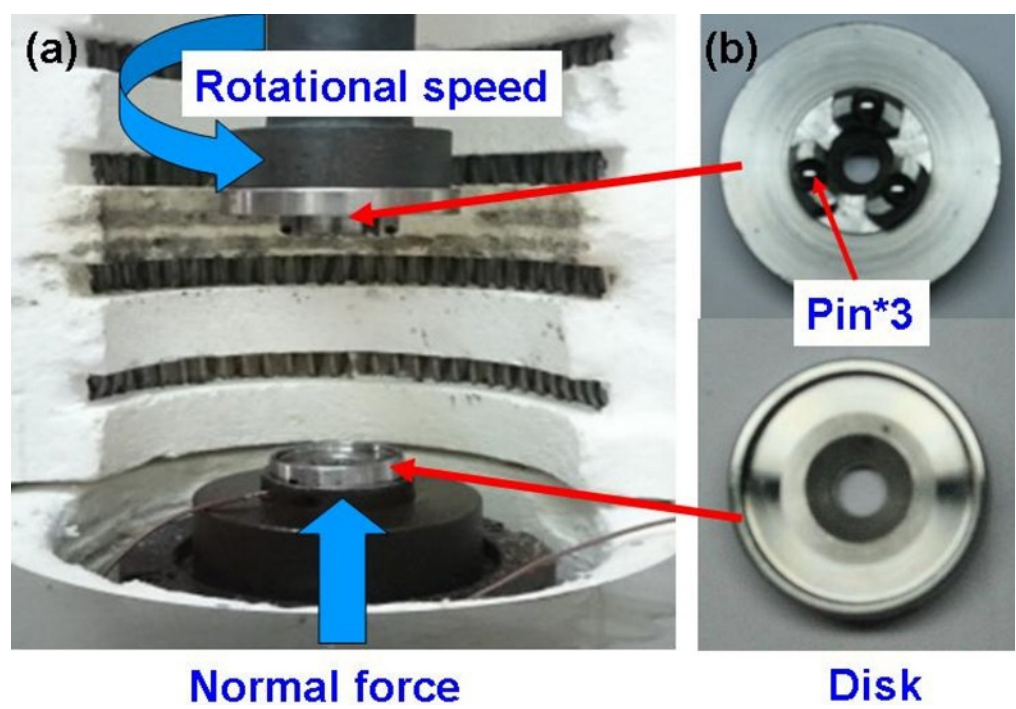

Figure 2. Inside the chamber: (a) chamber and (b) pin-on-disk apparatus.

\section{Real Scooter Test}

After the wear loss test, the optimal wear performance of NAEO is the best candidate to prevent high friction between the cylinder wall and the piston in a 125 c.c. scooter spark ignition engine. In Figure 3, a scooter was equipped on a chassis dynamometer. An auto-pilot machine was used to clamp the handlebar (throttle actuator), which was controlled by a servo motor. In the experiments, three test scenarios were conducted. The first was the constant vehicle speed test ( $50 \mathrm{kph}$ ), the second was the time-variant test (driving cycle), and the third was a test of four constant throttle positions. As shown in Figure 4, a common time-variant driving test scenario for light-duty vehicles-the ECE40 driving cycle-was selected. It includes three acceleration periods, and the maximal speed is $50 \mathrm{kph}$. The real vehicle speed must track the demanded vehicle speed well at each sampling time so that the retrieved data is convincing. This is because the values of consumed power (energy) for all tests are consistent. Before and after the standard driving cycle test, the difference of fuel weight was measured by the electric balance. Figure 4 shows that the tracking performance was good and confirms the applicability of the dynamometer test. 


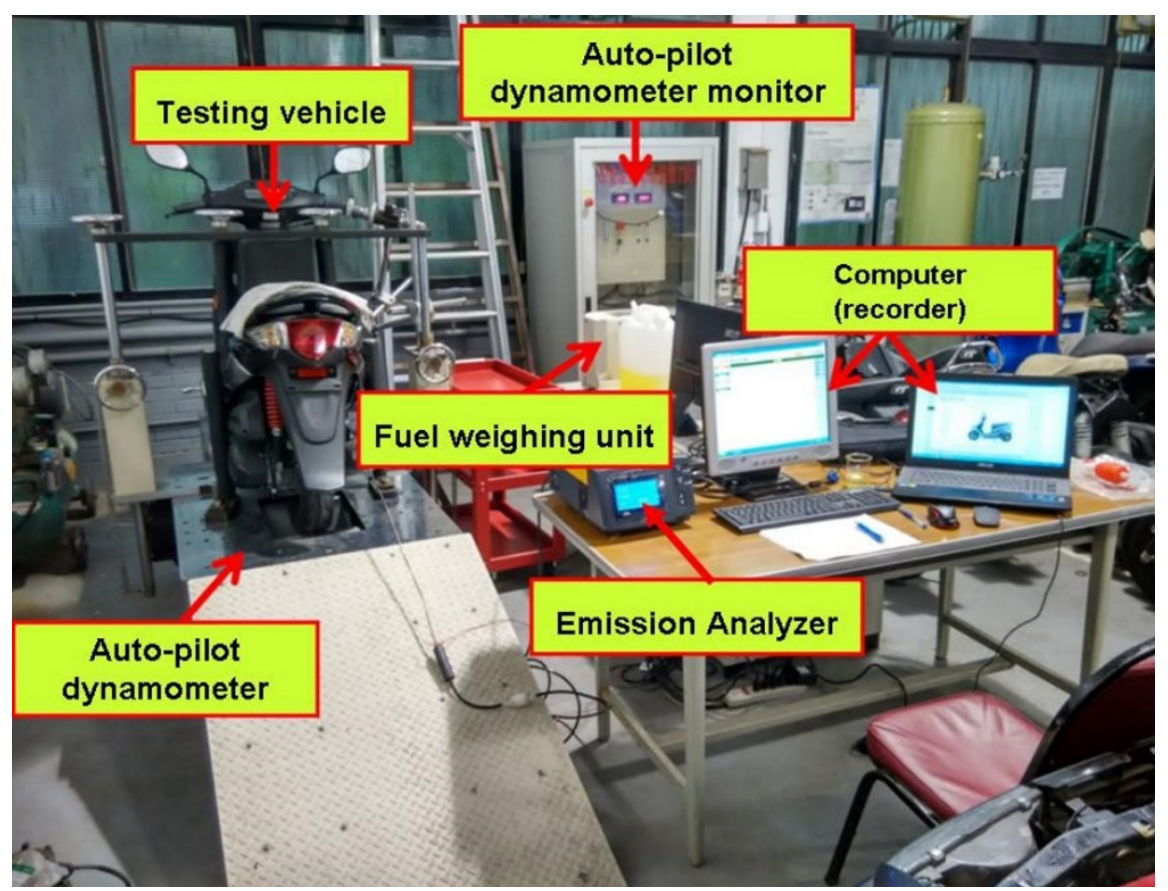

Figure 3. Dynamometer test for a scooter with a 125 c.c. engine.

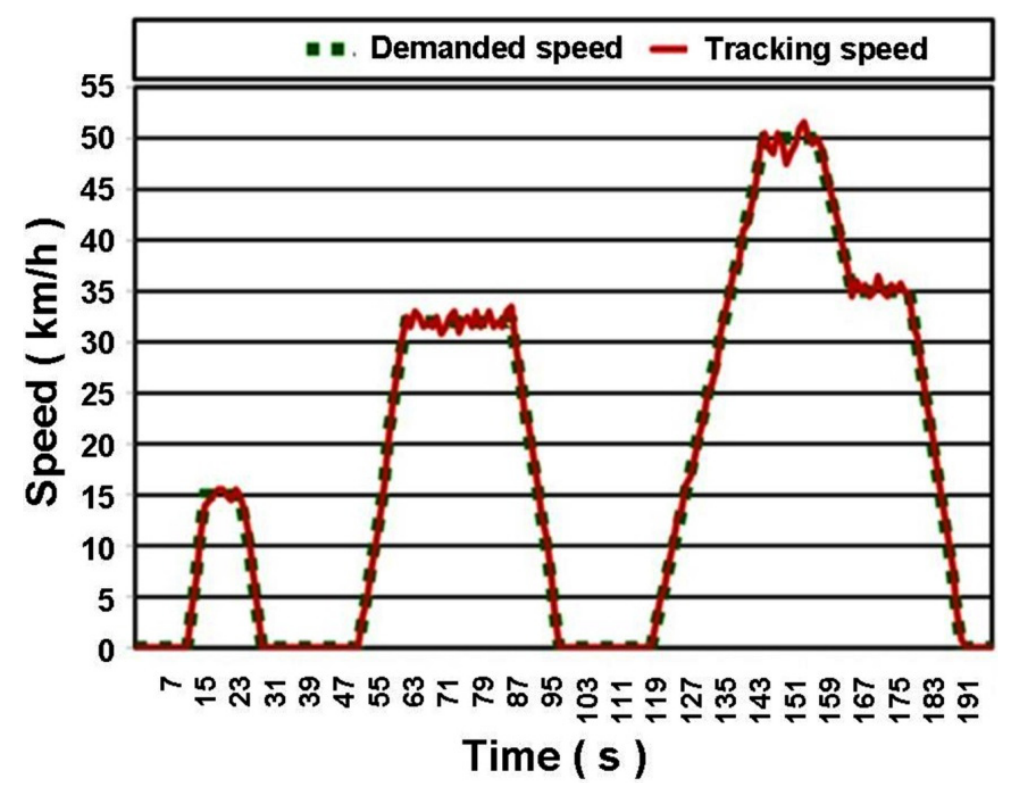

Figure 4. Demanded speed and tracking speed of the ECE40 driving cycle.

\section{Results and Discussion}

From Figure 5a, the higher the density of the test sample at the higher weight fraction was due to the higher density of the nanoparticles themselves. With higher test sample temperatures, the density dropped because of increased volume expansion. From Figure 5b, with more nanoparticles added, the viscosity was higher due to the interfacial relationship between the solid particles and the liquid molecules. In Figure $5 c$, the lower specific heat of the test sample at the higher weight fraction was due to the lower specific heat of the nanoparticles themselves. 


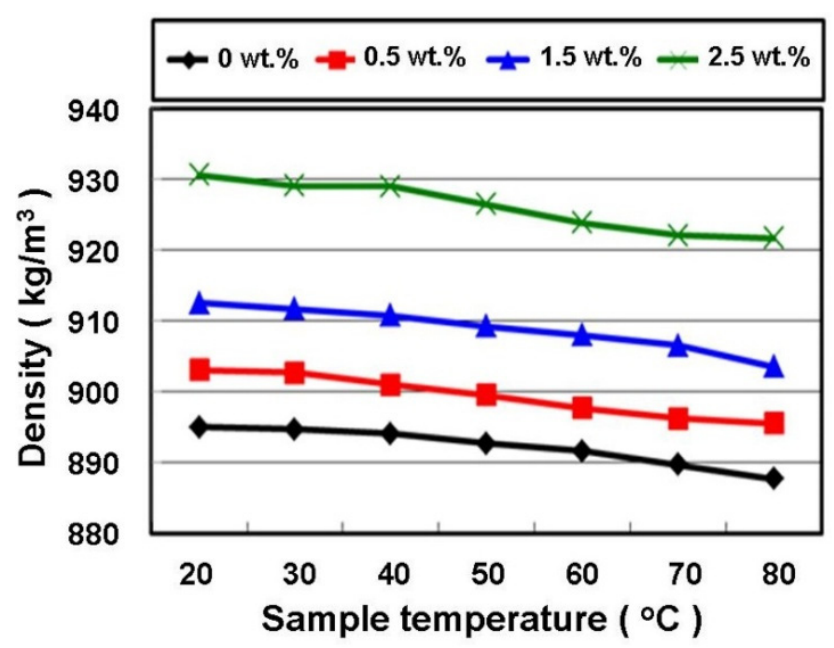

(a)

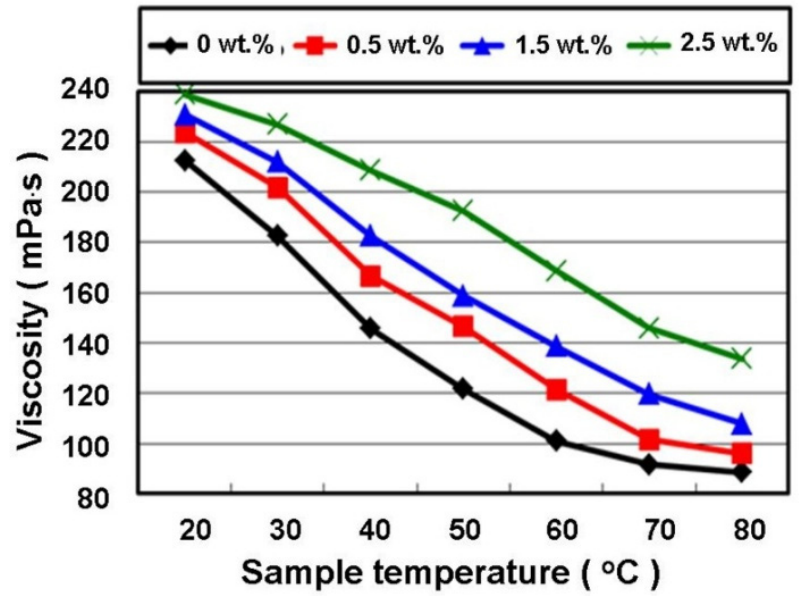

(b)

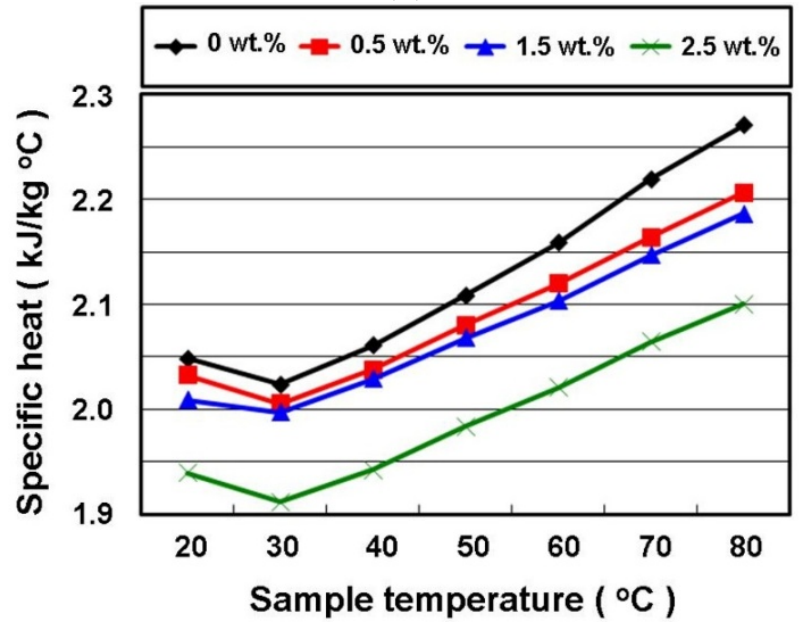

(c)

Figure 5. Basic properties of engine oil (EO) and nano-alumina engine oil (NAEO): (a) density; (b) viscosity; and (c) specific heat.

The influence of specific heat and density of the NAEO at various weight fractions was not significant, because the added weight fraction was low based on the concept of a solid-liquid mixture. Therefore, the effect of the specific heat and density of the NAEO on the wear performance and loading of the mechanical parts should be relatively small. However, the viscosity of the $2.5 \mathrm{wt}$. \% NAEO was 
significantly higher than the EO. It is noteworthy that the higher weight-fraction $\mathrm{Al}_{2} \mathrm{O}_{3}$-NAEO with higher viscosity did not flow easily; therefore, the highly-viscous NAEO was difficult to clean from the surface of the disk. Consequently, the inability to remove debris from the disk surface may cause an increase in interface roughness between the fixed and movable elements, causing an increase in wear weight loss. However, the shear thinning behavior of the NAEO at high rotating speeds may partly solve the problems described above $[9,19,22]$. Therefore, the search for the optimal weight fraction of NAEO must include a wear test to confirm the optimal performance of the specific weight fraction.

Figure 6 displays the wear loss of the NEAO with various weight fractions and normal forces at constant rotating speeds of 500 and $1000 \mathrm{rpm}$. For the weight fractions, it shows that the $1.5 \mathrm{wt} . \%$ has better anti-wear performance. This is because at lower weight-fraction NAEO ( $<1.5 \mathrm{wt} . \%)$, the amount of nanoparticles decreases so that the protection and anti-wear effects decrease, causing the wear loss to increase. With a higher weight-fraction NAEO (>1.5 wt. \%), though the amount of nanoparticles increases, debris will be trapped near the surface and cannot be released because the higher weight-fraction NEAO has higher viscosity. Therefore, the wear loss also increases. Overall, higher rotational speeds will indeed result in higher wear loss.

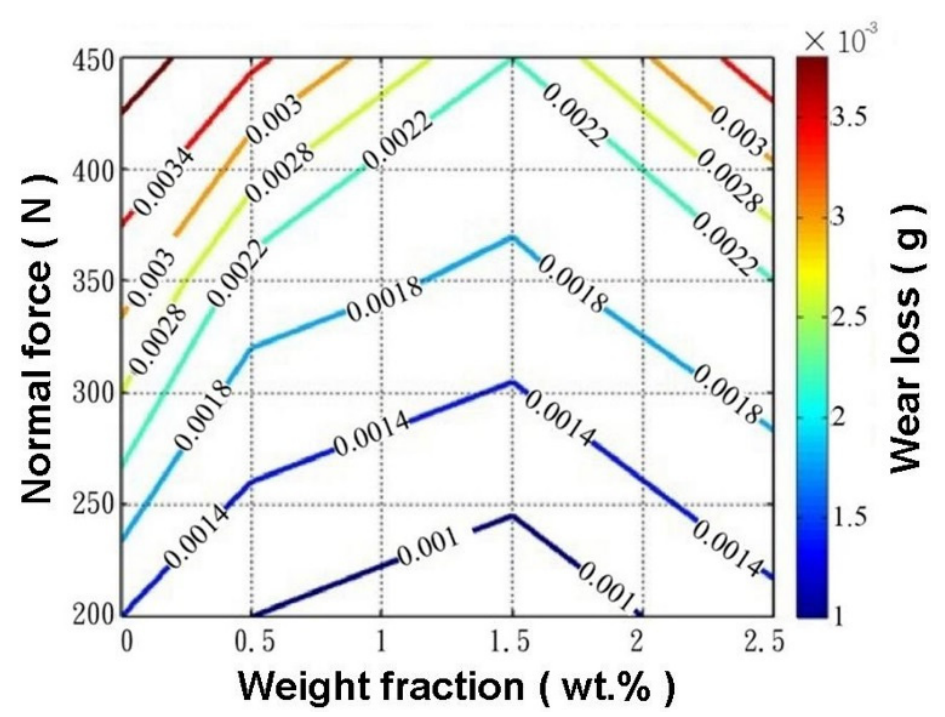

(a)

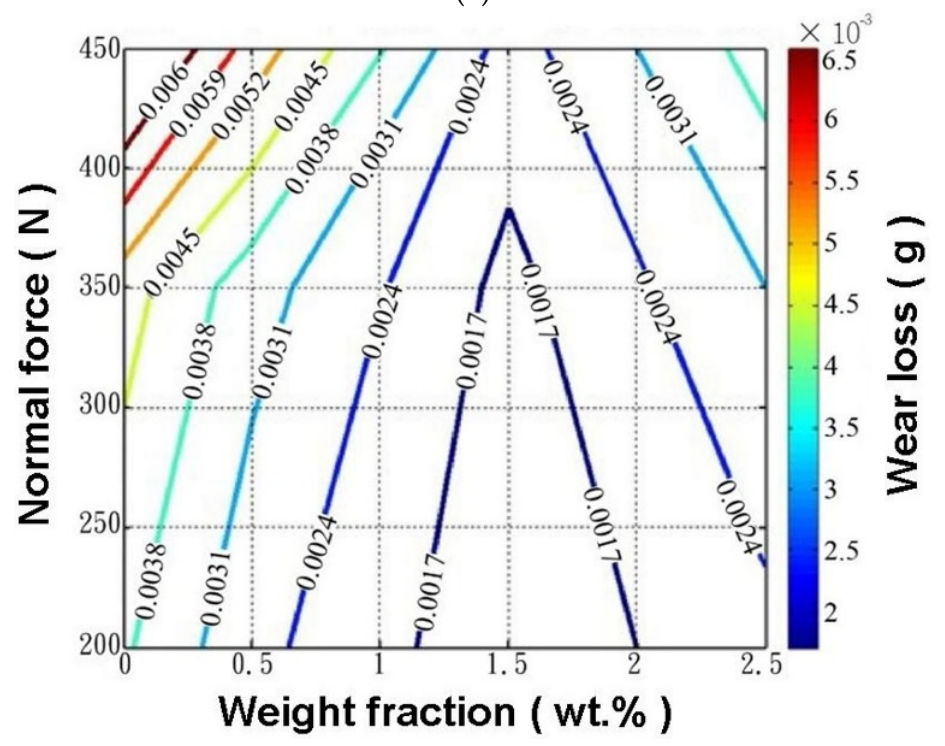

(b)

Figure 6. Wear loss with various weight fractions and normal forces at (a) $500 \mathrm{rpm}$ and (b) $1000 \mathrm{rpm}$. 
Figure 7 illustrates the wear loss at four weight fractions of the $\mathrm{Al}_{2} \mathrm{O}_{3}$ nanoparticles at various rotating speeds with a constant normal force of $350 \mathrm{~N}$. For the weight fractions, it shows that the $1.5 \mathrm{wt}$. \% has better anti-wear performance, because in a lower weight-fraction NAEO $(<1.5 \mathrm{wt}$. \%), the amount of nanoparticles decreases so that the protection and anti-wear effects decrease, causing the friction to increase. With a higher weight-fraction NAEO (>1.5 wt. \%), though the amount of nanoparticles increases, the debris will be trapped near the surface and cannot be released. Therefore, the wear loss also increases. Overall, higher normal force will indeed result in higher wear loss.

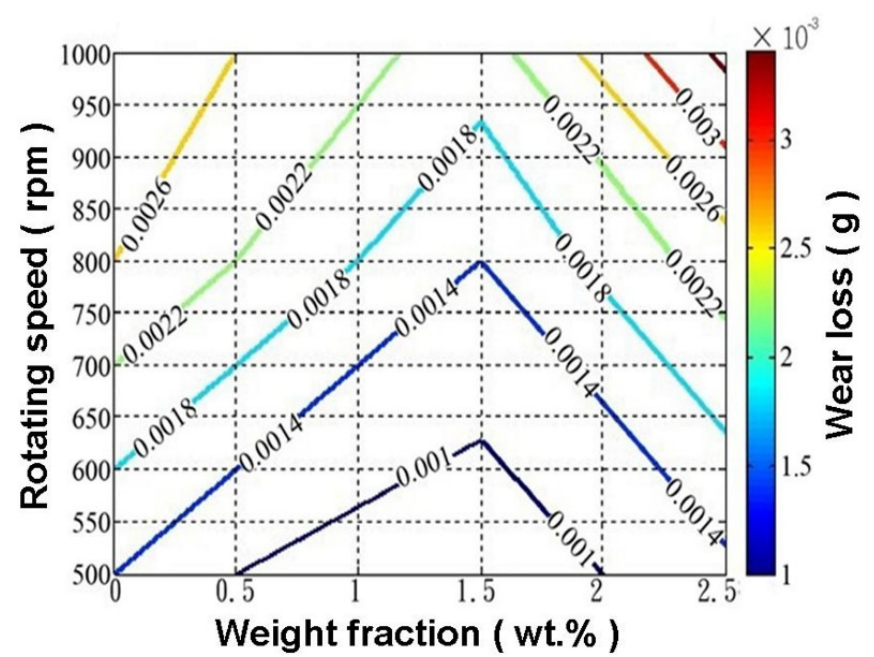

(a)

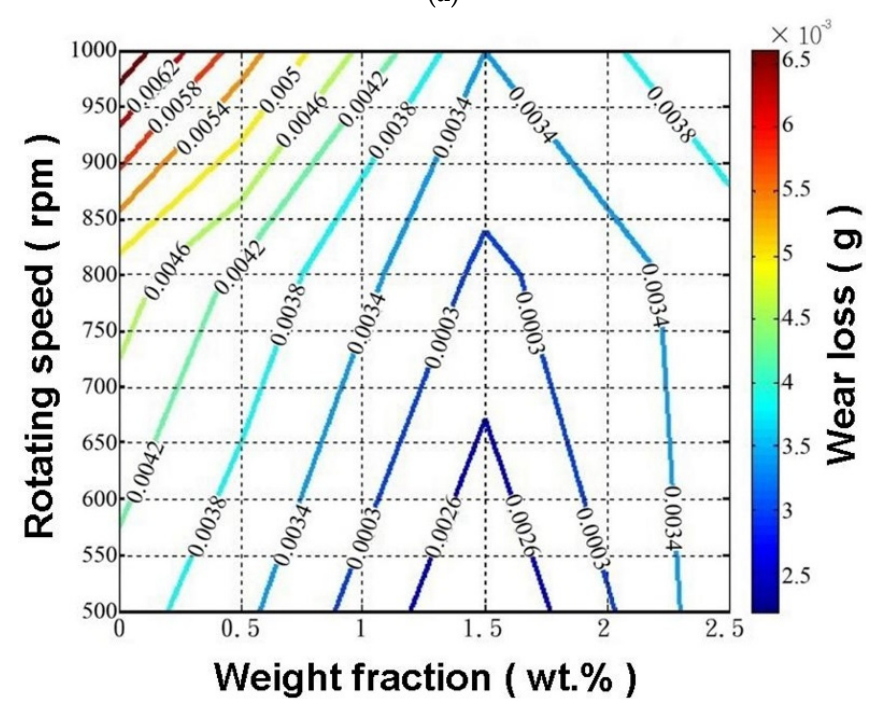

(b)

Figure 7. Wear loss with various weight fractions and rotating speeds at (a) $350 \mathrm{~N}$ and (b) $450 \mathrm{~N}$ normal forces.

Since 1.5 wt. \% NAEO had the best anti-wear performance (see Figures 6 and 7), the wear loss of 0 wt. \%, $1.5 \mathrm{wt}$. \%, and 2.5 wt. \% NAEO at various rotating speeds and normal forces is shown in Figure 8. Figure 8 shows that with higher speed (at the same normal force on the disk), the wear effect is more obvious. Similarly, at higher normal force and with the same rotating speed of the disk, the wear increases. This is because with either higher normal force or rotating speed, the amount of debris from the disk surface caused an increase in interface roughness between the pin and disk; thereby, it caused an increase in wear loss. Experimental results displayed in Figure 8 further confirm that the $1.5 \mathrm{wt}$. \% NEAO had the best anti-wear performance. 


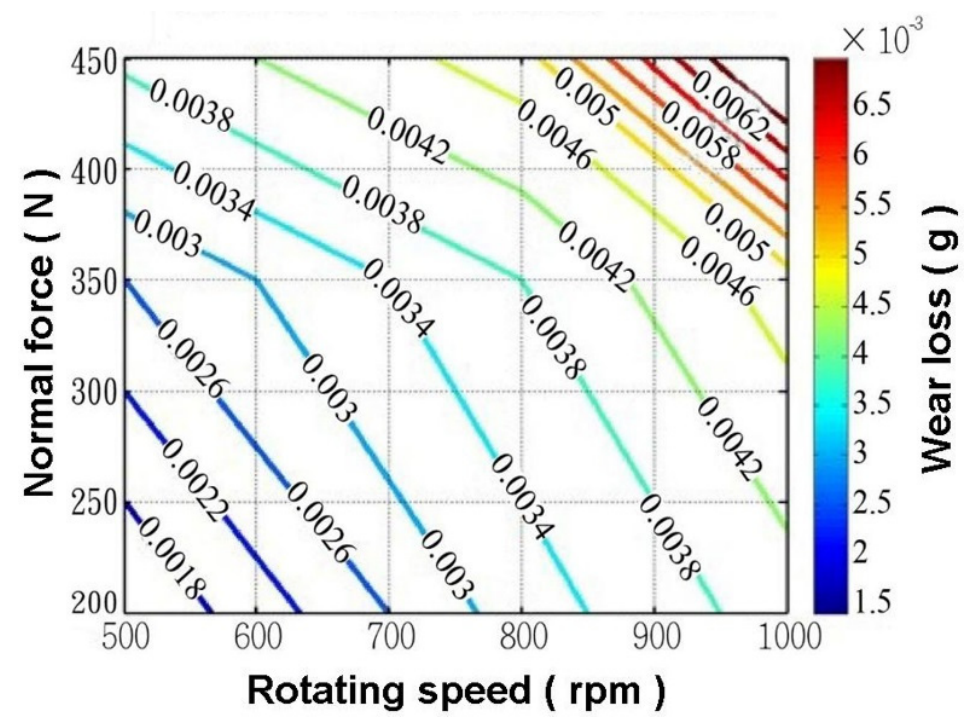

(a)

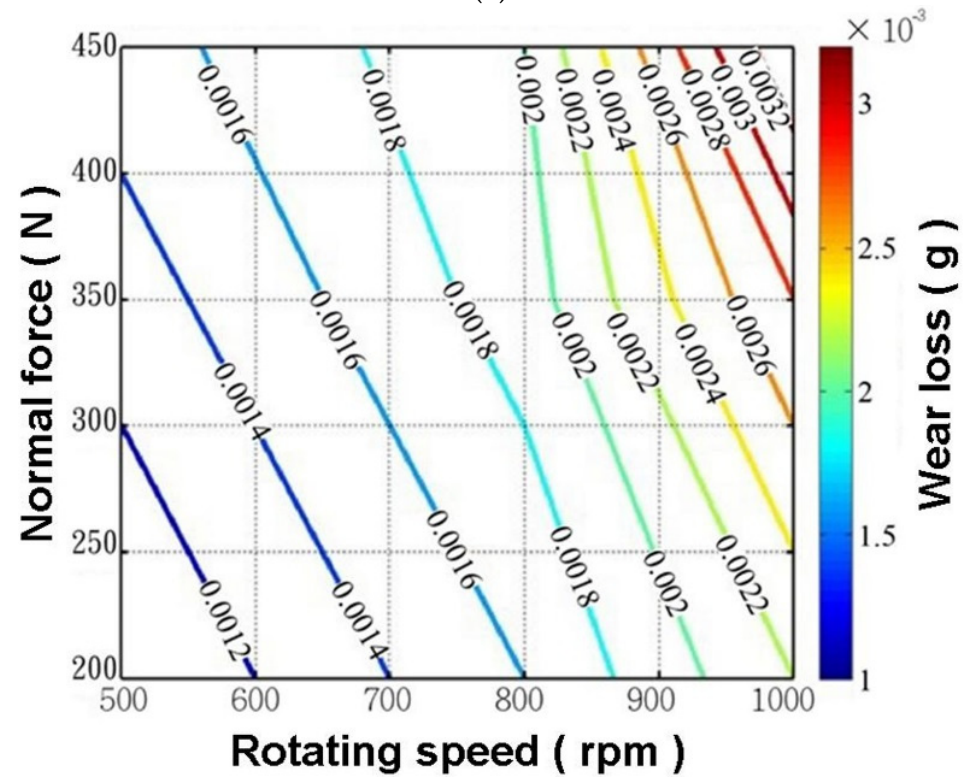

(b)

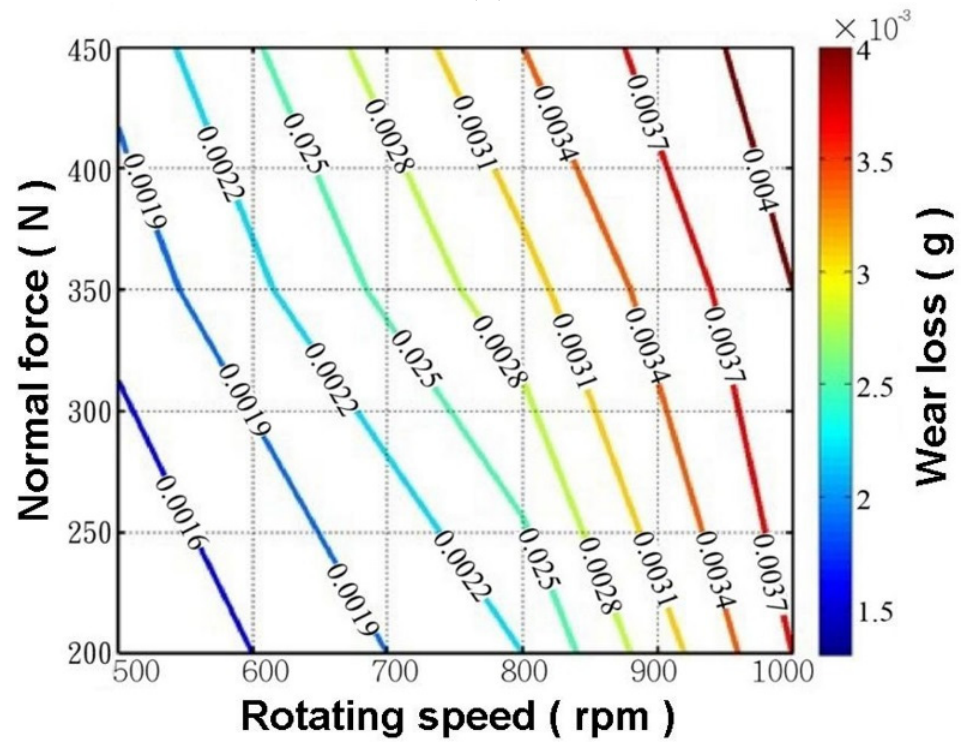

(c)

Figure 8. The wear loss of (a) 0 wt. \%; (b) 1.5 wt. \%; and (c) 2.5 wt. \% nano-alumina $\left(\mathrm{Al}_{2} \mathrm{O}_{3}\right)$ engine oil (NAEO) at various rotating speeds and normal forces. 
Regarding the anti-wear performance of test samples from Figures 6-8, the wear loss of the disk was lower for the $1.5 \mathrm{wt}$. \% NAEO than for the EO. However, the NAEO with a higher weight fraction of $\mathrm{Al}_{2} \mathrm{O}_{3}$ did not guarantee a more favorable anti-wear performance. This phenomenon primarily occurred because the higher weight fraction NAEO with higher viscosity flows more uneasily. Therefore, the highly-viscous NAEO was difficult to clean from the surface of the disk; consequently, the inability to remove debris from the disk surface caused an increase in interface roughness between the pin and disk. This then caused an increase in wear loss. However, the nano-oils may reduce wear loss by the the rolling-sliding effect, by providing a protective film, by third-body effect, by the mending and smoothing effect of surface roughness, by shear thinning, and by the high thermal conductivity of nano-oils. The effects mentioned above can reduce the wear loss of test samples. These effects, combined with the effect of viscosity, thereby determine the optimal nanoparticle weight fraction in nano-oils. Therefore, the optimal tribological performance was observed in the NAEO with $1.5 \mathrm{wt}$ \% $\mathrm{Al}_{2} \mathrm{O}_{3}$ nanoparticles; moreover, the wear loss of the $1.5 \mathrm{wt}$. $\% \mathrm{Al}_{2} \mathrm{O}_{3}$-NAEO was lower than that of the EO. Therefore, the $1.5 \mathrm{wt}$. \% NAEO and EO were selected as the test samples for the dynamometer test.

For the real scooter test on the dynamometer, each experimental item was tested three times for the average value. The experimental results of fuel consumption are shown in Figure 9. For the constant speed test $(50 \mathrm{~km} / \mathrm{h})$, the fuel consumption of the EO was $58.10 \mathrm{~km} / \mathrm{L}$, while the fuel consumption of the NAEO was $59.35 \mathrm{~km} / \mathrm{L}$. This shows that the improvement in fuel consumption comparing the NAEO to EO is $2.15 \%$. For the ECE40 driving cycle, the fuel consumption of the EO was $38.35 \mathrm{~km} / \mathrm{L}$, while the fuel consumption of the NAEO was $37.23 \mathrm{~km} / \mathrm{L}$. The improvement of fuel consumption comparing the NAEO to the original engine oil is $3.01 \%$. The average fuel consumption is defined as:

$$
F C_{\text {avg }}=1 /\left(0.6 / F C_{E C E}+0.4 / F C_{\text {const }}\right)
$$

where $F C_{a v g}, F C_{E C E}$, and $F C_{\text {const }}$ represent the average fuel consumption, fuel consumption of the ECE cycle, and the fuel consumption at constant speed, separately. The average fuel consumption for the EO is calculated to be $43.48 \mathrm{~km} / \mathrm{L}$, while it was $44.67 \mathrm{~km} / \mathrm{L}$ for the NAEO case according to Equation (1). Therefore, the fuel consumption improvement for the NAEO was calculated to be $2.75 \%$. Figure 10 illustrates the comparison of the original EO and NAEO at four constant throttle positions $(20 \%, 40 \%$, $60 \%$, and $90 \%$ ). Each experimental item was tested three times. For throttle position at $20 \%$, the fuel consumption for EO was $54.35 \mathrm{~km} / \mathrm{L}$, while it was $55.62 \mathrm{~km} / \mathrm{L}$ for the NAEO case. The improvement was $2.28 \%$. For throttle position at $40 \%$, the fuel consumption for EO was $56.20 \mathrm{~km} / \mathrm{L}$, while it was $58.95 \mathrm{~km} / \mathrm{L}$ for the NAEO case. The improvement was $4.66 \%$. For throttle position at $60 \%$, the fuel consumption for EO was $54.32 \mathrm{~km} / \mathrm{L}$, while it was $56.95 \mathrm{~km} / \mathrm{L}$ for the NAEO case. The improvement was $4.62 \%$. For $90 \%$ throttle position, the fuel consumption for EO was $53.45 \mathrm{~km} / \mathrm{L}$, while it was $55.63 \mathrm{~km} / \mathrm{L}$ for the NAEO case. The improvement was 3.92\%. The average fuel improvement for the four throttle positions was $3.87 \%((2.28+4.66+4.62+3.92) \% / 4)$. The above experiments prove that the $1.5 \mathrm{wt}$. \% NAEO truly improves the wear performance, and the fuel consumption either in transient dynamics or in steady-state simulation while operating the spark ignition engine of the scooter was decreased. For future studies, experiments with property tests of other nano-engine oils and a performance assessment of the nano-engine fuel (or EO) will be conducted. 


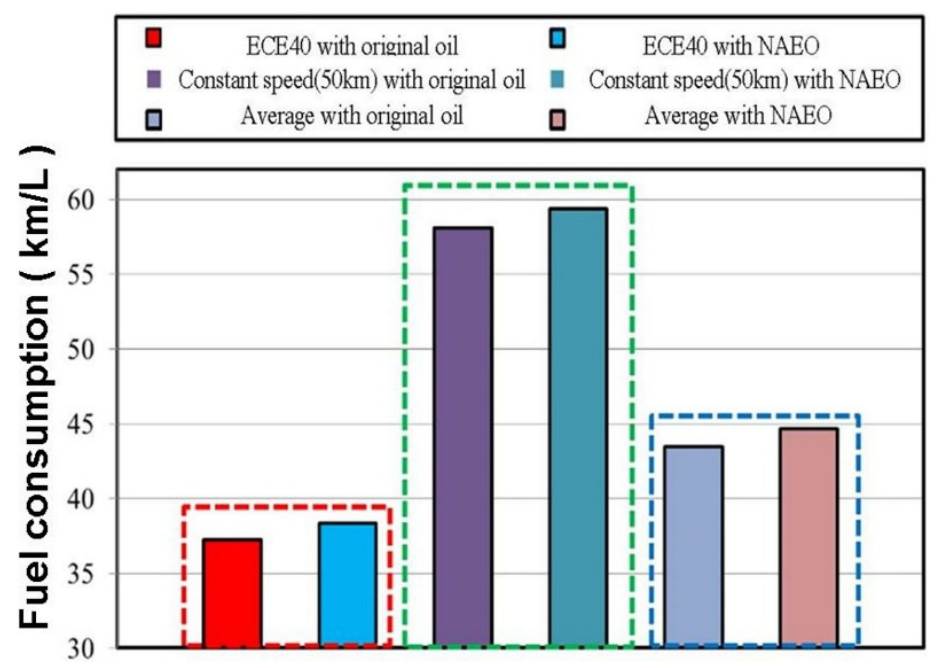

Figure 9. Comparison of fuel consumption between the engine oil and the NAEO (driving cycle and constant speed).

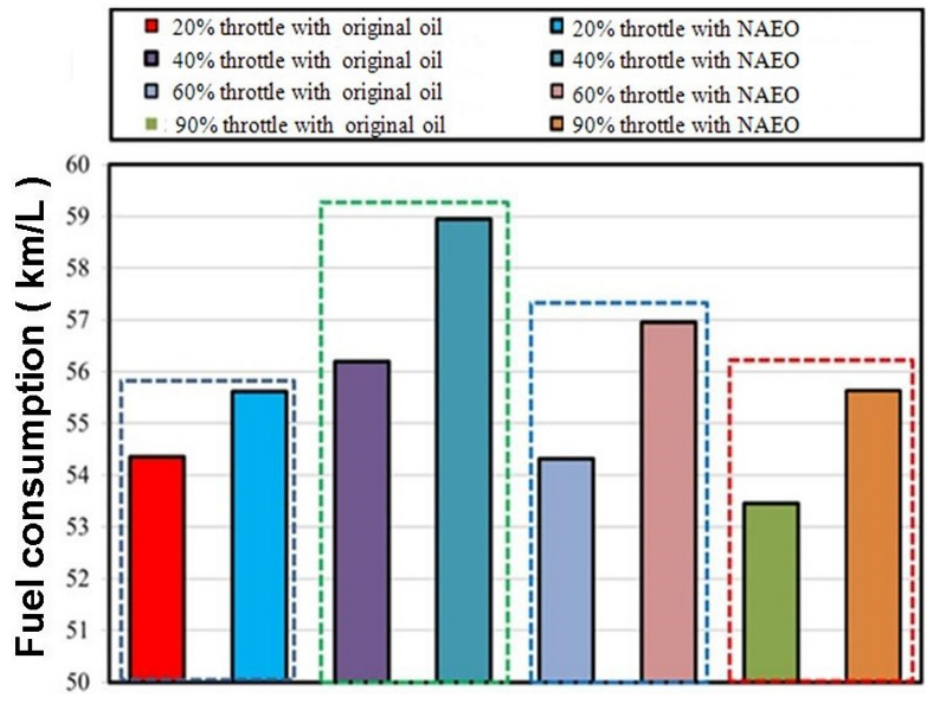

Figure 10. Comparison of fuel consumption between the engine oil and the NAEO (throttle position at $20 \%, 40 \%, 60 \%$, and $90 \%$ ).

\section{Conclusions}

This study conducted a performance evaluation of NAEO for use in the spark ignition (SI) engine of a scooter. The academic and industrial contributions are as follows:

(1) Basic properties of NAEO: four test samples with weight fractions were set at 0 (non-additive), 0.5 wt. $\%, 1.5$ wt. $\%$, and 2.5 wt. \%. The experimental evaluation of density and viscosity at various sample temperatures $\left(20-80^{\circ} \mathrm{C}\right)$ was conducted.

(2) Wear test on the platform of NAEO: A tribology testing machine with a pin-on-disk apparatus was established for the wear test. Results prove that $\mathrm{NAEO}$ with $1.5 \mathrm{wt} . \% \mathrm{Al}_{2} \mathrm{O}_{3}$ nanoparticles (1.5 wt. \% NAEO) demonstrated the best wear performance.

(3) Real scooter implementation: the $1.5 \mathrm{wt}$. \% NAEO was added to the SI engine of a scooter. A dynamometer test emulated the road load to evaluate the performance. The ECE40 driving cycle, the constant speed case, and four cases of constant throttle position were conducted. Results proved that the fuel consumption for ECE40 and constant speed was decreased on average by $2.75 \%$, while a reduction of $3.87 \%$ was seen for the constant throttle position cases. 
For future works, experiments with property tests of other nano-engine oils and a performance assessment of the nano-engine fuel will be conducted.

Acknowledgments: The authors would like to thank the Ministry of Science and Technology of Republic of China (Taiwan) for their financial support to this research under Contract No. MOST 104-2221-E-003-025-, MOST 105-2221-E-003 -017-MY3, and MOST 105-2221-E-003-019-.

Author Contributions: Y.-F.L. and Y.-H.H. conceived of the study. Y.-F.L., Y.-H.H. and F.-S.L. designed the experimental procedure. F.-S.L., T.-P.T. and C.-H.W. fabricated the samples and carried out the measurements. Y.-F.L., Y.-H.H., F.-S.L., T.-P.T., S.-Y.C. and Y.-C.O. performed the test system calibration and analyzed the measurements. Y.-H.H. and T.-P.T. wrote the paper. All authors read and approved the final manuscript.

Conflicts of Interest: The authors declare no conflict of interest.

\section{References}

1. Hung, Y.H.; Teng, T.P.; Teng, T.C.; Chen, J.H. Assessment of Heat Dissipation Performance for Nanofluid. Appl. Therm. Eng. 2012, 32, 132-140. [CrossRef]

2. Lomascolo, M.; Colangelo, G.; Milanese, M.; de Risi, A. Review of heat transfer in nanofluids: Conductive, convective and radiative experimental results. Renew. Sustain. Energy Rev. 2015, 43, 1182-1198. [CrossRef]

3. Sarkar, J.; Ghosh, P.; Adil, A. A review on hybrid nanofluids: Recent research, development and applications. Renew. Sustain. Energy Rev. 2015, 43, 164-177. [CrossRef]

4. Ali, M.K.A.; Hou, X. Improving the tribological behavior of internal combustion engines via the addition of nanoparticles to engine oils. Nanotechnol. Rev. 2015, 4, 347-358. [CrossRef]

5. Dai, W.; Kheireddin, B.; Gao, H.; Liang, H. Roles of nanoparticles in oil lubrication. Tribol. Int. 2016, 102, 88-98. [CrossRef]

6. Ali, M.K.A.; Hou, X.; Turkson, R.F.; Peng, Z.; Chen, X. Enhancing the thermophysical properties and tribological behaviour of engine oils using nano-lubricant additives. RSC Adv. 2016, 6, 77913-77924.

7. Ettefaghi, E.; Ahmadi, H.; Rashidi, A.; Mohtasebi, S.S.; Alaei, M. Experimental evaluation of engine oil properties containing copper oxide nanoparticles as a nanoadditive. Int. J. Ind. Chem. 2013, 4, 28. [CrossRef]

8. Babu, K.S.; Nair, K.P.; Rajendrakumar, P.K. Computational analysis of journal bearing operating under lubricant containing $\mathrm{Al}_{2} \mathrm{O}_{3}$ and $\mathrm{ZnO}$ nanoparticles. Int. J. Eng. Sci. Technol. 2014, 6, 34-42. [CrossRef]

9. Dinesh, R.; Prasad, M.J.G.; Kumar, R.R.; Jerome Santharaj, N.; Santhip, J.; Raaj, A.S.A. Investigation of tribological and thermophysical properties of engine oil containing nano additives. Mater. Today Proc. 2016, 3, 45-53. [CrossRef]

10. Laad, M.; Jatti, V.K.S. Titanium oxide nanoparticles as additives in engine Oil. J. King Saud Univ. Eng. Sci. 2016. [CrossRef]

11. Ali, M.K.A.; Hou, X.; Liqiang, M.; Cai, Q.; Turkson, R.F.; Chen, B. Improving the tribological characteristics of piston ring assembly in automotive engines using $\mathrm{Al}_{2} \mathrm{O}_{3}$ and $\mathrm{TiO}_{2}$ nanomaterials as nano-lubricant additives. Tribiol. Int. 2016, 103, 540-554. [CrossRef]

12. Zhang, M.; Wang, X.; Liu, W.; Fu, X. Performance and antiwear mechanism of Cu nano-particles as lubricating additives. Ind. Lubr. Tribol. 2009, 61, 311-318. [CrossRef]

13. Choi, C.; Jung, M.; Choi, Y.; Lee, J.; Oh, J. Tribological properties of lubricating oil-based nanofluids with metal/carbon nanoparticles. J. Nanosci. Nanotechnol. 2011, 11, 368-371. [CrossRef] [PubMed]

14. Vadiraj, A.; Manivasagam, G.; Kamani, K.; Sreenivasan, V.S. Effect of nano oil additive proportions on friction and wear performance of automotive materials. Tribol. Ind. 2012, 34, 3-10.

15. Zin, V.; Agresti, F.; Barison, S.; Colla, L.; Gondolini, A.; Fabrizio, M. The synthesis and effect of copper nanoparticles on the tribological properties of lubricant oils. IEEE Trans. Nanotechnol. 2013, 12, 751-759. [CrossRef]

16. Chu, H.Y.; Hsu, W.C.; Lin, J.F. The anti-scuffing performance of diamond nano-particles as an oil additive. Wear 2010, 268, 960-967. [CrossRef]

17. Wang, B.; Wang, X.; Lou, W.; Hao, J. Rheological and tribological properties of ionic liquid-based nanofluids containing functionalized multi-walled carbon nanotubes. J. Phys. Chem. C 2010, 114, 8749-8754. [CrossRef]

18. Hsin, Y.L.; Chu, H.; Jeng, Y.; Huang, Y.; Wang, M.H.; Chang, C.K. In situ de-agglomeration and surface functionalization of detonation nano-diamond, with the polymer used as an additive in lubricant oil. J. Mater. Chem. 2011, 21, 13213-13222. [CrossRef] 
19. Asadi, M.; Asadi, A. Dynamic viscosity of MWCNT/ZnO-engine oil hybrid nanofluid: An experimental investigation and new correlation in different temperatures and solid concentrations. Int. Commun. Heat Mass Transf. 2016, 76, 41-45. [CrossRef]

20. Afrand, M.; Najafabadi, K.N.; Akbari, M. Effects of temperature and solid volume fraction on viscosity of $\mathrm{SiO}_{2}-\mathrm{MWCNTs} / \mathrm{SAE} 40$ hybrid nanofluid as a coolant and lubricant in heat engines. Appl. Therm. Eng. 2016, 102, 45-54. [CrossRef]

21. Rasheed, A.K.; Khalid, M.; Javeed, A.; Rashmi, W.; Gupta, T.C.S.M.; Chan, A. Heat transfer and tribological performance of graphene nanolubricant in an internal combustion engine. Tribol. Int. 2016, 103, 504-515. [CrossRef]

22. Esfe, M.H.; Afrand, M.; Yan, W.M.; Yarmand, H.; Toghraie, D.; Dahari, M. Effects of temperature and concentration on rheological behavior of $\mathrm{MWCNTs} / \mathrm{SiO}_{2}(20-80)-\mathrm{SAE} 40$ hybrid nano-lubricant. Int. Commun. Heat Mass Transf. 2016, 76, 133-138. [CrossRef]

23. Lee, K.; Hwang, Y.; Cheong, S.; Kwon, L.; Kim, S.; Lee, J. Performance evaluation nano-lubricants of fullerene nanoparticles in refrigeration mineral oil. Curr. Appl. Phys. 2009, 9, e128-e131. [CrossRef]

24. Jwo, C.S.; Jeng, L.Y.; Chang, H.; Chen, S.L. Research of vacuum pump with nano-lubricant. Key Eng. Mat. 2008, 364-366, 867-872. [CrossRef]

25. Binu, K.G.; Shenoy, B.S.; Rao, D.S.; Pai, R. A variable viscosity approach for the evaluation of load carrying capacity of oil lubricated journal bearing with $\mathrm{TiO}_{2}$ nanoparticles as lubricant additives. Proc. Mater. Sci. 2014, 6, 1051-1067. [CrossRef]

26. Rapoport, L.; Leshchinsky, V.; Lvovsky, M.; Nepomnyashchy, O.; Volovik, Y.; Tenne, R. Mechanism of friction of fullerenes. Ind. Lubr. Tribol. 2002, 54, 171-176. [CrossRef]

27. Chiñas-Castillo, F.; Spikes, H.A. Mechanism of action of colloidal solid dispersions. J. Tribol. 2003, 125, 552-557. [CrossRef]

28. Wu, Y.Y.; Tsui, W.C.; Liu, T.C. Experimental analysis of tribological properties of lubricating oils with nanoparticle additives. Wear 2007, 262, 819-825. [CrossRef]

29. Hu, Z.S.; Lai, R.; Lou, F.; Wang, L.G.; Chen, Z.L.; Chen, G.X.; Dong, J.X. Preparation and tribological properties of nanometer magnesium borate as lubricating oil additive. Wear 2002, 252, 370-374. [CrossRef]

30. Zhou, J.; Yang, J.; Zhang, Z.; Liu, W.; Xue, Q. Study on the structure and tribological properties of surface-modified Cu nanoparticles. Mater. Res. Bull. 1999, 34, 1361-1367. [CrossRef]

31. Zhou, X.; Fu, X.; Shi, H.; Hu, Z. Lubricating properties of Cyanex 302-modified $\mathrm{MoS}_{2}$ microspheres in base oil 500SN. Lubr. Sci. 2007, 19, 71-79.

32. Rapoport, L.; Leshchinsky, V.; Lapsker, I.; Volovik, Y.; Nepomnyashchy, O.; Lvovsky, M.; Popovitz-Biro, R.; Feldman, Y.; Tenne, R. Tribological properties of $\mathrm{WS}_{2}$ nanoparticles under mixed lubrication. Wear 2003, 255, 785-793. [CrossRef]

33. Liu, G.; Li, X.; Qin, B.; Xing, D.; Guo, Y.; Fan, R. Investigation of the mending effect and mechanism of copper nano-particles on a tribologically stressed surface. Tribol. Lett. 2004, 17, 961-966.

34. Wan, Q.; Jin, Y.; Sun, P.; Ding, Y. Tribological behaviour of a lubricant oil containing boron nitride, nanoparticles. Proc. Eng. 2015, 102, 1038-1045. [CrossRef]

35. Peng, D.X.; Chen, C.H.; Kang, Y.; Chang, Y.P.; Chang, S.Y. Size effects of $\mathrm{SiO}_{2}$ nanoparticles as oil additives on tribology of lubricant. Ind. Lubr. Tribol. 2010, 62, 111-120. [CrossRef]

36. Nunn, N.; Mahbooba, Z.; Ivanov, M.G.; Ivanov, D.M.; Brenner, D.W.; Shenderova, O. Tribological properties of polyalphaolefin oil modified with nanocarbon additives. Diam. Relat. Mater. 2015, 54, 97-102. [CrossRef]

37. Choi, Y.; Lee, C.; Hwang, Y.; Park, M.; Lee, J.; Choi, C.; Jung, M. Tribological behavior of copper nanoparticles as additives in oil. Curr. Appl. Phys. 2009, 9, e124-e127. [CrossRef]

38. Mansot, J.L.; Bercion, Y.; Romana, L.; Martin, J.M. Nanolubrication. Braz. J. Phys. 2009, 39, $186-197$. [CrossRef]

39. Alawi, O.A.; Sidik, N.A.C.; Beriache, M. Applications of nanorefrigerant and nanolubricants in refrigeration, air-conditioning and heat pump systems: A review. Int. Commun. Heat Mass Transf. 2015, 68, 91-97. [CrossRef]

40. Khalil, A.N.M.; Alib, M.A.M.; Azmi, A.I. Effect of $\mathrm{Al}_{2} \mathrm{O}_{3}$ nanolubricant with SDBS on tool wear during turning process of AISI 1050 with minimal quantity lubricant. Procedia Manuf. 2015, 2, 130-134. [CrossRef]

41. Padmini, R.; Krishna, P.V.; Rao, G.K.M. Effectiveness of vegetable oil based nanofluids as potential cutting fluids in turning AISI 1040 steel. Tribol. Int. 2016, 94, 490-501. [CrossRef] 
42. TA Instruments. Sapphire Specific Heat Capacity Literature Values, Thermal Applications Note (TN-8A). Available online: http://www.tainstruments.co.jp/application/pdf/Thermal_Library/Applications_Notes / TN008.PDF (accessed on 9 August 2016).

43. ASTM. G99-95a, Standard Test Method for Wear Testing with a Pin-on-Disk Apparatus; ASTM International: West Conshohocken, PA, USA, 2000.

44. Lue, Y.F.; Li, F.S.; Teng, T.P.; Hsu, Y.C.; Hung, Y.H. Basic properties and wearing performance of mineral oil with adding nano particles. In Proceedings of the 31th CSME Conference, Taichung, Taiwan, 6-7 December 2014. (In Chinese)

45. Lue, Y.F.; Hsu, Y.C.; Teng, T.P. Performance evaluation on vacuum pumps using nanolubricants. J. Mech. Sci. Technol. 2016, in press.

(C) 2016 by the authors; licensee MDPI, Basel, Switzerland. This article is an open access article distributed under the terms and conditions of the Creative Commons Attribution (CC-BY) license (http:/ / creativecommons.org/licenses/by/4.0/). 